\title{
Professoras e rainhas do lar: o protagonismo feminino na imprensa periódica (1902-1940)*
}

\section{Teachers and queens of home: female protagonism in periodical press (1902-1940)}

\author{
Jamilly Nicácio Nicolete** \\ Jane Soares de Almeida***
}

\begin{abstract}
RESUMO
Os anos iniciais do século XX contaram com uma imprensa periódica que exigia mais direitos para as mulheres, educação, instrução e o voto. Essa imprensa foi influenciada pela imprensa internacional que se veiculava no país em número suficiente e a preços acessíveis. As revistas e jornais vinham principalmente dos Estados Unidos e da Europa, que, nesse momento, se agitava em torno do feminismo e dos tempos de guerra. Os periódicos, de longa ou curta duração, esporadicamente contemplavam ideias acerca do papel das mulheres na sociedade, mas nem sempre havia unanimidade em sua ideologia e representação do protagonismo feminino. Com seu beneplácito, vieram à luz as expectativas de segmentos intelectualizados da sociedade brasileira, em especial nas maiores cidades do país, como São Paulo e Rio de Janeiro, no tocante à educação das mulheres e sua destinação para a maternidade, conjuntamente com a educação de crianças. A abordagem adotada volta-se para os conceitos da História da Educação, história das mulheres, estudos de gênero e imprensa.
\end{abstract}

Palavras-chave: Educação. História da Educação. História das mulheres. Gênero. Imprensa.

\section{DOI: $10.1590 / 0104-4060.50841$}

* Artigo referente a projeto financiado pelo Conselho Nacional de Desenvolvimento Científico e Tecnológico (CNPq) na modalidade Bolsa de Produtividade em Pesquisa.

** Centro Universitário Toledo. Araçatuba, São Paulo, Brasil. Rua Jardim Sumaré, no 595 Jardim Sumaré. CEP: 16015-270. E-mail: jamillynicacio@hotmail.com

*** Universidade de Sorocaba. Sorocaba, São Paulo, Brasil. Rodovia Raposo Tavares, Km 100. Vila Artura. CEP: 18023-000. E-mail: janesoaresdealmeida@uol.com.br 


\begin{abstract}
The early years of the Twentieth Century have seen a periodical press that demanded greater rights, education and voting for women. This press release was influenced by the international press that ran in the country at sufficient and affordable prices. Magazines and newspapers came mainly from the United States and Europe at that time; both places were shaken by the times of war and the movements of feminism at the time. Periodicals of longer or shorter duration occasionally reflected on ideas about the role of women in society, though there was not always unanimity in their ideology and representation of the female role. With their approval, the expectations of intellectualized segments of Brazilian society began, especially in the larger cities of the country, concerning the women's task as the educators of children and their destiny of motherhood. The research issue is related to the magazines that emerged in the dawn of the century until the forties, selected as sources yet unexplored, given its rarity. Our approach turns to the concepts of the history of education, women's history, gender studies and press studies.
\end{abstract}

Keywords: Periodical Press. Teaching. Education. Gender. Feminism. Micro-History.

\title{
Introdução
}

No ordenamento social, a hierarquia menor ocupada pelas mulheres produziu um discurso de dominação que levou a extremadas consequências no jogo desigual do poder, com sua exclusão de aspectos importantes da historiografia, em especial quanto ao mundo público e as ramificações na economia e na política. Ater-se à fidedignidade das fontes para recuperar essa história, assim como sua possível confiabilidade, significa um passo arriscado na reconstrução histórica, principalmente quando o objeto de estudos pertence a segmentos com menor poder e influência na sociedade.

Como atribuir importância, nos rumos da economia e da política, para os(as) considerados(as) coadjuvantes no tecido social, como mulheres, negros, indígenas, homossexuais, idosos, deficientes, pobres, entre outros? O mundo é ordenado em esferas de poder, nas quais a escala axiológica se inicia no topo por sujeitos masculinos, brancos e poderosos economicamente. Como homogeneizar práticas iguais para atores sociais diferentes, do ponto de vista do poder social, o que representa as bases das aspirações da democracia? No caso das mulheres, isso não poderia ser efetivado pela posição secundária que ocuparam ao longo 
das décadas na escala social, pois estavam deslocadas do mundo público pela força do poder masculino.

A sociedade não homogênea centrada no poder patriarcal trouxe como consequência a discriminação prática e simbólica de homens a mulheres. Como detentores dos espaços de poder nas várias instâncias sociais, os sujeitos masculinos foram os encarregados de disseminar práticas culturais valorativas expressas nos mais diversos níveis, em especial nas representações sociais que eram divulgadas na imprensa periódica que crescia e formava opiniões, desde o século XIX, no território brasileiro, e se firmava nos novos estados republicanos economicamente desenvolvidos.

Nas diferenças praticadas pelo discurso ideológico da imprensa, pouco extenso e variado, solidificava-se um pensamento que pressupunha uma estrutura democrática da sociedade, erigida nas bases da família convencional e no respeito aos indivíduos. Uma ordenação social representada pelo casal e seus filhos, adeptos da privacidade do lar e ao respeito dos valores morais e cristãos, era divulgada a partir do século XIX, como espelhamento de uma sociedade sadia e uma pátria poderosa. O distanciamento proporcionado pelo futuro (hoje), junto ao passado histórico, pode dar a ilusão de um mundo de direitos e deveres repartidos por igual na esfera social e conjugal, como direitos e deveres na criação dos filhos, na solidificação dos relacionamentos conjugais legitimados pela sociedade civil e pela Igreja Católica e na preservação da intimidade. Afastada da sacralidade desses espaços, uma barreira intransponível se erigia para o sexo feminino, enquanto, para os homens, liberdade e autonomia eram direitos garantidos e aceitos.

$\mathrm{Na}$ imprensa periódica representada pelos jornais diários, os fatos se processavam rapidamente ao sabor do momento. Não cabiam, nessa antiga imprensa, as inquietações femininas que se debatiam com as expectativas sociais, resguardadas no recesso dos lares das influências, ditas maléficas, do mundo público. Essas inquietações, no entanto, aconteciam principalmente numa imprensa menor, na qual pequeno número de mulheres com conhecimentos intelectuais escrevia reclamando por mais direitos. ${ }^{1}$

O trabalho de Magaldi, ao estudar o jornal católico A Ordem, publicado nos anos 1930, refere-se a uma hierarquia no campo social "como um movimento chave na organização da sociedade brasileira" (MAGALDI, 2008, p. 86). Esta

1 Conceituo imprensa menor, não num sentido de desqualificação, mas de diferenciar da imprensa representada pelos grandes jornais diários formadores de opiniões com público mais abrangente. Essa pequena imprensa possuía duração efêmera, escassa distribuição e muitas vezes aconteciam longos intervalos entre as publicações. Enquadram-se nessa categoria as revistas femininas, as educacionais, alguns panfletos, os manuais de civilidade e etiqueta, os livros religiosos, os almanaques, entre outros. (NA). 
surgiu ao lado de outros pilares sociais, como tradição, disciplina e autoridade. Mesmo assim, as hierarquias de gênero se mantinham, dadas serem consideradas apropriadas ao modelo de sociedade defendido pelos católicos:

Tendo como foco essas relações, pode-se observar que a desigualdade e a hierarquia mostram-se visíveis nas páginas da revista A Ordem, por meio da ausência da mulher, no início dos anos 1930. Até esse momento, se a voz feminina não era praticamente ouvida, temas relativos à vida da mulher também não eram objeto de grande atenção nos artigos da revista. (p. 86). [...]. Cabe lembrar que tal presença era fortemente estimulada pelas lideranças católicas, podendo a identificação feminina com aquele movimento ser aferida por meio da própria revista A Ordem, em que chama a atenção o número significativo de artigos publicados por mulheres, desde meados da década de 1930 e ao longo da década seguinte, focalizando a temática da Ação Católica, tanto numa perspectiva de análise, quanto de convocação à participação feminina (MAGALDI, 2008, p. 97).

Nos grandes jornais paulistas: O Estado de S. Paulo e a Folha de S. Paulo, por exemplo, estampavam-se notícias sobre economia, política interna e externa, notas sobre homens públicos. Nas esparsas notas dirigidas ao público feminino, a publicidade avisava sobre algum novo utensílio doméstico importante para ajudar as donas de casa nos seus labores. Afinal era assim que o mundo público representava sua imagem e simbolismo: as rainhas do lar.

Com os grandes jornais de ampla circulação interpondo objetivamente, e nas entrelinhas, uma visão doméstica sobre as mulheres que as levava inevitavelmente ao papel de exímias donas de casa, nesse espaço, realizando suas maiores aspirações. Como confiar nas fontes impressas para reinterpretar sua história? Como se equilibrarem no fio tênue que oscilava perante a imagem das mulheres sedutoras, de passado obscuro e de futuro incerto, desejadas pelos homens, e as mulheres, ditas honestas, que viam o manejo dos lares e o desempenho materno como o ápice de seus destinos? São confiáveis as fontes impressas? De acordo com Campos (2012), esta é uma questão a ser verificada:

Para aqueles que buscam a veracidade objetiva na fonte, nada menos confiável do que a imprensa. Entretanto, para os historiadores que buscam pistas verossímeis sobre o passado, talvez aí esteja nada mais próximo da cultura de um tempo. Aqueles que compreendem que qualquer fonte histórica, e não apenas os jornais, necessita ser problematizada não apenas 
em relação ao que está (ou não) escrito, mas também em relação a como está escrito; aqueles que compartilham da crença de que toda fonte é parcial e fragmentada por excelência, contendo mesmo uma boa dose de ficção, não se atemorizam diante de tais relatos de autores. Antes de tudo, caminham ao lado da comprovação da parcialidade das fontes, fazendo dessa realidade a sua verdade possível. [...]. Significa levar em conta além do já mencionado repertório cultural dos envolvidos na sua leitura/escrita, também os interesses econômicos e ideológicos envolvidos na sua edição. Significa reconhecer e problematizar o espaço gráfico dado para esta ou aquela crônica, propaganda, notícia ou artigo. Significa transformá-los também num objeto de pesquisa (CAMPOS, 2012, p. 66).

Uma vez problematizada a necessidade de dar sentido e significado às fontes impressas representadas pela imprensa periódica, ressaltando sua possível fidedignidade (ou não), resta aos historiadores se equilibrar numa inconsútil rede de aspirações e conspirações para reconstruir os estilhaços e os fragmentos de um espelho partido, buscando se aproximar do real.

A denominada grande imprensa se revela excessivamente omissa quanto ao sexo feminino, ao disseminar a cultura vigente de ornamentos de salões ou perfeitas donas de casa, o que se prolongou ao século XX e ainda tem profundo impacto no século XXI, acrescido, com a maior liberdade feminina, de transformar as mulheres em objetos sexuais no mundo da publicidade, representação disseminada exaustivamente nos meios de comunicação.

Como reconstruir os fragmentos do espelho? Se esses, por vezes encontrados na imprensa menor, além de não totalmente confiáveis, também são esparsos, dada a pouca preservação histórica dessas fontes. Essa é uma questão ideológica e também ontológica. Um texto, impresso ou efetuado como discurso, é emblemático do que se pensa ou que se fala. A interpretação resulta do conhecimento - oculto ou explícito - de quem lê e recepta, "como uma proposição de mundo", conforme denomina Ricoeur (1988, p. 56).

Será que dialogamos com as fontes segundo nosso desejo e nossas expectativas? Será que, ao buscarmos o significado oculto da fonte histórica, não estamos propondo que se consolide e se justifique nossa hipótese? As fontes documentais fornecem informações que possibilitam complementar a reconstrução histórica. A questão é: como levar a efeito uma análise que possa fazer a interpretação do discurso escrito de forma a produzir um conhecimento com validade científica como o exige um trabalho dessa natureza? Para o deslindamento dessa questão impõe-se uma reflexão filosófica que indique as vias teóricas a serem utilizadas, no sentido que lhe atribui Ricoeur (1978, p. 8): "O próprio trabalho da interpretação revela um desígnio profundo: o de superar uma distância, um afastamento 
cultural, o de equiparar o leitor a um texto que se tornou estranho e, assim, incorporar seu sentido à compreensão presente que um homem pode obter dele mesmo". Existe assim uma relação originária entre o conceito de interpretação e o de compreensão. A linguagem do texto escrito, devidamente interpretada, leva à apreensão do significado - dessa forma, interpretar é transportar-se para outra vida, instaurando o paradoxo de como um ser histórico pode compreender historicamente a história. Se a interpretação é apreensão do sentido e a realidade não se reduz apenas à experiência sensível, identificando-se com o que pode ser dito, a linguagem como mediação simbólica com o mundo é veículo capaz de instaurar o sentido (RICOEUR, 1978).

Toda interpretação se propõe a vencer um afastamento, uma distância, entre a época cultural à qual pertence o texto e o próprio intérprete no momento da leitura. Essa interpretação não é uma tarefa simples e existe uma grande distância entre as formulações teóricas e sua aplicabilidade. Entretanto, seu maior mérito reside no seu potencial de utilização; ou seja, a possibilidade, do ponto de vista da História Cultural, de estabelecer categorias explicativas derivadas das próprias fontes e o máximo de conhecimentos que delas pode-se auferir. Para isso, situar historicamente o personagem impõe-se como uma necessidade, assim como o desvendamento da sua inserção cultural, econômica e social, recorrendo ao imaginário da época que se traduz em depoimentos, cartas, textos, letras de música, fotos, diários, poesias, onde a visão de mundo dos atores sociais se entrecruza com a realidade, traduz e até mesmo a modifica, dando-lhe seus próprios contornos. Ao mesmo tempo, há que se fazer uma decodificação da cultura da época, dos hábitos e dos costumes, que possibilite o trânsito epistemológico da macroestrutura para as realizações do dia a dia.

Esse caráter multifacetado implica em diversificar as fontes a serem utilizadas, recorrendo a materiais como manuscritos, relatórios, manuais, livros e compêndios, exercícios escolares, cartilhas, fragmentos da literatura erudita e popular, canções, provérbios, jornais e revistas pedagógicas e femininas, panfletos feministas, almanaques, legislação específica, assim como as imagens representadas pelas fontes iconográficas para a reconstrução histórica. Entrelaçar as representações acerca das mulheres e homens e sua educação, em meio a esse variado e fecundo conjunto de documentos, possibilita uma aproximação com o universo social e educativo do período, com suas rupturas e continuidades. Pretende-se assim uma edificação das interfaces permitidas pelas fontes, visando uma aproximação com as matrizes analíticas que impliquem em uma reconstrução o mais fiel possível, dado o distanciamento que a história impõe aos pesquisadores.

Para este artigo foram recolhidas fontes que não estavam representadas na chamada grande imprensa, mas aquelas parcialmente ocultas nos vários arquivos 
visitados, contando com os resultados de um trabalho paciente e minucioso. Nem sempre as revistas, os manuais, os jornais efêmeros e os almanaques estavam nas bibliotecas, arquivos ou nos centros de memória das instituições de pesquisa, mas às vezes eram encontrados de forma aleatória ou doados por pessoas que os colecionaram ao longo do tempo. Impõe-se, assim, novamente a ideia de vestígios da passagem de atores sociais ausentes de protagonismo destacada, como no caso das mulheres (ALMEIDA, 1998, 2015). Foram essas fontes, quase desconhecidas em alguns casos, que ajudaram compor o tecido da pesquisa. Essas fontes não preencheram lacunas, mas mostraram possibilidades para reinterpretar os sentidos ou significados, mesmo o campo sendo limitado.

\section{Mulheres, imprensa e educação: as interfaces do mundo social}

As décadas iniciais do século $\mathrm{XX}$, como período de protestos femininos em busca de mais direitos, em especial o voto e a educação formal, promoveram o que já vinha se edificando no século XIX. O reconhecimento de que a outra metade da humanidade possuía aspirações, não limitadas apenas à maternidade e ao desempenho doméstico, numa prática de submissão estruturada em séculos anteriores, deu os passos iniciais rumo à maior autonomia feminina.

$\mathrm{Na}$ asserção de que o equipamento biológico natural não era passível de clarificar as diferenças existentes entre homens e mulheres, foi possível um novo olhar que pudesse considerar o protagonismo das mulheres na história, abandonando-se o enfoque naturalista. Este enfoque, ao alijar do feminino a condição de seres políticos e históricos, que serviu, nos tempos anteriores, para justificar os mecanismos de opressão e submissão de origem sexual, passou a ser questionado na imprensa da época em nível internacional nos países do Ocidente, o que, presumivelmente, ocasionou avanços na situação feminina, em especial nas esferas intelectualizas e de melhor poder aquisitivo.

No Brasil, nas primeiras décadas do século XX, o magistério representou uma das escassas oportunidades profissionais para as mulheres. $\mathrm{O}$ fato de não terem amplo acesso às demais profissões fez da docência a opção mais adequada para o sexo feminino, o que foi reforçado pelos atributos de missão e vocação, além da continuidade no trabalho do lar.

A transformação histórica do magistério, desempenhado por professoras e não mais apenas professores, esteve ligada às alterações nas relações patriarcais que, há algum tempo, vinham reestruturando a sociedade nas primeiras décadas do novo século. Para os homens, quando o magistério era uma ocupação 
casual que tomava menos tempo, podia ser exercida conjuntamente com outras profissões, como medicina, direito, engenharia, jornalismo e sacerdócio, e representava um meio a mais para quem queria obter notoriedade e ampliar os ganhos, sem deixar de exercer sua ocupação principal, com destinação exclusivamente masculina.

A crença na inferioridade intelectual feminina, respaldada pelo Positivismo nos anos que antecederam à República, originava-se, principalmente, na recusa em educar as mulheres - a não ser nas lides domésticas e para brilhar socialmente, assíduas frequentadoras de saraus e salões de baile -, enquanto aguardavam o futuro pretendente que as retiraria do lar paterno e lhes concederia o trono de rainhas no novo lar que a sociedade erigia. A ideologia burguesa intentava mantê-las confinadas no espaço doméstico e essa domesticidade era desejada e mantida a todo o custo. Positivistas e higienistas foram determinantes para conseguir alicerçar a concepção de mulheres-mães, guardiãs dos lares, esposas extremosas, sublimes e dispostas a sacrifícios em nome de outrem. A imprensa periódica, escrita e dirigida por homens, ignorava as diferenciações sexuais no ensino e referia-se aos professores e às professoras de uma maneira uniforme e nas contracapas dos jornais e revistas os homens eram retratados frequentemente, porém o mesmo não sucedia com as mulheres que trabalhavam como professoras (ALMEIDA, 1998).

O Anuário de Ensino do Estado de São Paulo registrou em 1889 um número de mulheres maior do que o dos homens nas matrículas na Escola Normal (51 alunos e 64 alunas), sendo que em 1912, na Escola Normal da capital, matricularam-se 172 rapazes e 768 moças e formaram-se, nesse mesmo ano, 24 professores e 120 professoras (ANUÁRIO DO ENSINO DO ESTADO DE SÃO PAULO, 1912, p. 69). Embora o Rio de Janeiro representasse o polo cultural do país, São Paulo, no princípio do século, já se estruturava como uma futura metrópole; visto que em 1890 estava em terceiro lugar com 1.384 .750 habitantes, logo depois de Minas Gerais e Bahia. Em 1940 saltaria para o primeiro lugar com 7.239.711 (O ESTUDANTE, 1943, p. 20). Isso repercutiu nos meios de comunicação, em especial no fortalecimento da imprensa periódica nacional que se desenvolvia nos maiores centros urbanos.

Em fins do século XIX, surgiu no Rio de Janeiro uma imprensa feminina dedicada aos interesses das mulheres, como $O$ Bello Sexo (1862), Echo das Damas (1879), A Família (1889), O Jornal das Senhoras (1852). Em Minas Gerais, Francisca Senhorinha da Motta Diniz publicou O Sexo Feminino (1873) e, no ano seguinte, $O$ Domingo (1874) foi fundado por Violante Atabalipa Ximenes de Bivar e Vellasco e, em Recife, Myosótis (1875), de Maria Heraclia. Dentre as principais revistas escritas e dirigidas por mulheres em São Paulo, 
destacaram-se A Mensageira, publicada de 1897 a 1900, e a Revista Feminina, ${ }^{2}$ que circulou de 1914 a 1936. Além dessas, surgiram algumas publicações menores, de duração efêmera, como O Mundo Feminino (1916); A Voz Maternal (1903); Ella, publicada na década de 1930; Leque (1887) e $A$ Violeta, no mesmo ano. (BUITONI, 1986).

O artigo "São Paulo de ontem e de hoje" (GUASTINI, 1936), publicado na revista $E l l a^{3}$, em abril de 1936, referia-se a uma cidade que em 1902 denunciava a grande capital que viria a ser, embora com resquícios de província. $\mathrm{Na}$ imprensa paulista, os jornalistas eram figuras populares que todos apontavam com admiração e respeito, tão reduzido o seu número. As revistas estrangeiras como Vogue, Femina, Le Miroir eram assinadas pelas famílias, cuja situação econômica lhes permitia contato assíduo com os grandes centros da elegância europeia. Almanaques eram lidos com interesse e assinados pelas famílias. Eles traziam notícias dos centros culturais, de novos modos de vida do pós-guerra e das existências que transcorriam em países que se recuperavam após os anos de conflito. Os artigos publicados se referiam com frequência ao protagonismo social feminino, nem sempre defendendo sua exposição ao espaço público. No entanto, o contraponto existia; e as atrizes seminuas, os atletas, as cantoras, as bailarinas, as herdeiras de grandes fortunas se exibiam no espaço público.

\begin{abstract}
Portanto, a empreitada "arqueológica" dos jornais - expressão consagrada pelos que tomaram Roger Chartier como referencial teórico - em muito se assemelha àquela tal noção empreendida em relação às revistas, mas sem dúvida não pode ser empregada sob a mesma acepção para gêneros discursivos diferentes, os quais apresentam, cada qual, um estilo ou modo de presença próprios: o jornal e a revista. Se o sentido da fonte jornal é diferente do sentido da fonte revista, em comum no trato de ambos está a operação de crítica interna e externa do documento, já que desde tempos imemoriais intuímos que todo e qualquer registro deve ser historicizado perse. (CAMPOS, 2012, p. 58)
\end{abstract}

O imaginário masculino acerca da figura feminina continuou prendendo-se aos padrões tradicionais que nem o pós-Primeira Guerra nem as mudanças

2 A Revista Feminina e seu desenvolvimento em São Paulo, publicada por 22 anos, foi objeto de estudos de Sonia Amorim Mascaro (1982); Dulcídia Schoeder Buitoni (1981, 1986); Sandra Lúcia Lopes Lima (1991) e Maria Cândida Delgado Reis (1993).

3 ELLA, revista feminina, quinzenal, ilustrada, em artigo de abertura do $\mathrm{n}^{\circ} 1$, publicado em 15 de abril de 1936, de autoria de Mário Guastini, ex-diretor do Jornal do Comércio. 
sociais intentaram diluir. Atente-se, porém, que no Estado Novo o regime político cerceador das liberdades individuais era uma realidade. Ao referir-se ao feminismo, muitas vezes os articulistas o contrapunham à feminilidade, "qualidade" que deveriam ter todas as mulheres, e o classificava como um fator de desequilíbrio social. Esse desequilíbrio revelava-se ao incutir nas mulheres as ideias pouco apropriadas ao seu sexo e ao que delas se esperava em termos sociais e familiares, além de estar em oposição à natureza espiritual do povo brasileiro. A emergência dessas novas mulheres, necessariamente, deveria vir acompanhada de uma educação adequada que as preparasse para os cuidados com o lar e lhes possibilitasse uma inserção no campo profissional. Apesar disso, não foram poucos os que se opuseram ferozmente à ideia de mulheres instruídas e profissionalizadas, principalmente os pertencentes ao catolicismo ultraconservador que via na ascensão feminina à instrução, uma ameaça.

Em 1902, a Revista de Ensino apresentou o artigo Normalistas, assinado por Jenny Maia:

Após a formatura começa a verdadeira luta da professora em obter uma cadeira, dado que a maioria não veio estudar por mero luxo, mas porque precisava sobreviver. Todas querem uma colocação nos Grupos Escolares da Capital, pois não se resignam a ir trabalhar longe no interior. Porém o máximo que podem conseguir é uma escola em uma estação de estrada de ferro ou em um bairro qualquer. E aí teremos uma moça solteira, bem-educada, mas naturalmente fraca a viajar sozinha todos os dias, sujeita aos desaforos dos malcriados, ou às eventualidades de uma viagem, embora curta. (...) felizes aquelas que lá mesmo na escola encontram o esposo, que lhes será companheiro para educar e ensinar não só os filhos dos outros, como os próprios filhos! A solução única é procurar um marido, que a ampare, que a proteja, e que possa mais facilmente conseguir, por sua influência eleitoral, melhoria de condições para a professora desterrada. Os quatrocentos mil réis atraem os pretendentes e não faltará quem queira ter a profissão de marido de professora para viver de seu ordenado, sem fazer coisa alguma (MAIA, 1902, p. 924).

Concepção similar também pode ser encontrada no romance $O$ Calvário de uma professora, publicado em 1928, com o pseudônimo Dora Lice, uma das escassas obras de literatura que abordam exclusivamente a profissão de professora e que apresenta a mesma visão negativa do magistério feminino. O livro é veemente ao ressaltar as qualidades das professoras e a sua dedicação, além de classificar os inspetores e diretores, ocupantes dos cargos de chefia na educação, 
de incompetentes, arrogantes, ignorantes e outros epítetos pouco qualificativos. O livro descreve como as professoras, dóceis e dedicadas, eram enviadas aos piores lugares, às escolas mais distantes. Nesses locais, eram maltratadas pelos colonos ignorantes e detestadas pelos pais dos alunos que não os queriam na escola por necessitar do seu trabalho na lavoura.

A Revista de Ensino em 1910 publicou artigo assinado por F. A. Berra (1910, p. 20), "Se as mulheres são preferíveis, ou não, aos homens para dar aos meninos a instrução primária". O escritor fazia referência ao sistema europeu, no qual existia um grande número de homens que se ocupavam de profissões pouco lucrativas, embora estivessem preparados para cargos bem remunerados. Esses homens, segundo o autor, dedicavam-se ao ensino primário. As mulheres, excluídas, por ideias e costumes absurdos, de quase todas as profissões e dos empregos e funções públicas, estavam geralmente condenadas à triste condição de parasitas. Porém, como as mulheres encontravam nas escolas, e o povo nas professoras, um meio de satisfazer necessidades físicas e morais, que sem elas não satisfariam, vinham as mulheres substituindo os homens no ensino primário sul-americano. $\mathrm{O}$ autor referia-se ao fato comumente aceito de que a inserção das mulheres no magistério foi uma concessão, quando se lhes permitiu ocupar os lugares abandonados pelos homens. A princípio, segundo afirmava, isso foi verdadeiro, e as mulheres foram admitidas nas escolas por necessidade, porque se teve que optar entre conformar-se com elas ou fechar os estabelecimentos de ensino (BERRA, 1910, p. 20).

\section{Homens e mulheres na imprensa periódica: nem mesmas faces, nem mesmas moedas}

$\mathrm{Na}$ análise do pensamento veiculado pela imprensa educacional e feminina, nada indica que, no ensino primário paulista, os homens tenham se ausentado da profissão, apesar de se divulgar essa ideia, assim como a de se reservar somente às mulheres esse ramo do ensino.

Nos discursos solenes transcritos na Revista de Ensino, estes são dirigidos sempre aos senhores professores e senhoras professoras, carissimos alunos e alunas. Na regulamentação da atividade feminina, ainda de acordo com o autor, devia ser reservado às mulheres o ensino primário e o pré-primário, local onde estas se destacariam e onde se lhes descortinariam os mais belos horizontes. Apesar disso, lamentava, as jovens brasileiras não se contentavam com isso e fugiam de seu grande sacerdócio nas cidades do interior do país, desejando exercê-lo apenas nas grandes cidades e na capital. 
O papel de educadoras da infância era o mais elevado que as mulheres poderiam aspirar. Como a educação nacional se impunha como a máxima necessidade de um Brasil que se renovava, nesse novo país um lugar importante estava destinado às mulheres e era representado pela culminante missão de ensinar. Caberia à nação dedicar toda sua atenção à educação das futuras educadoras que iriam desempenhar a alta e relevante carreira profissional do país, conforme assegurava o articulista Artur Negreiro Falcão, da revista Formação: "Enquanto, porém, se não alcança a era de tão ansiosos ideais de política nacional, devemos cuidar, olhando o amanhã, de opor óbices por uma regulamentação racional aos surtos invasores da mulher nas regiões burocráticas, o futuro da Pátria estaria seriamente ameaçado"”. (FALCÃO, 1941, p. 60-65).

As repercussões ao artigo dele devem ter sido muitas, pois nos números seguintes, os bacharelandos da Faculdade de Direito de Niterói, "atentos aos problemas sociais", publicaram um abaixo-assinado dirigido a Getúlio Vargas com o nome "A mulher e o serviço público", encaminhando "o belíssimo e oportuno artigo do citado autor". Os bacharelandos informavam ao presidente que, com a concorrência das mulheres nas atribuições dos homens, o futuro da pátria estaria ameaçado, conforme defendera Artur Negreiro Falcão. Não queriam, com essa atitude, combater as mulheres, pois seu grande desejo era:

[...] defendê-la e ampará-la; queremos que ela torne ao trono sagrado do lar onde os nossos antepassados a colocaram; queremos para ela a posição de respeito e veneração de que gozaram e ainda gozam nossas mães; queremos que ela volte a ser esposa de seu marido e mãe, no sentido lato, de seus filhos (FALCÃO, 1941, p. 61).

A intenção de alojar novamente as mulheres nos lares pressupunha como principal argumento a família e a certeza de sua desagregação se elas continuassem exercendo o trabalho fora do espaço doméstico. Os filhos ficariam abandonados em mãos de serviçais ignorantes, a quem pouco importava a formação do caráter infantil. As únicas pessoas capazes de educar os filhos à perfeição eram as mães e, para que fossem excelentes nas funções maternas, era necessário que não conhecessem profundamente as imperfeições dos ho-

4 Artur Negreiro Falcão, "A mulher e o serviço público", publicado em FORMAÇÃO-Revista Brasileira de Educação, janeiro de 1941, p. 60-65. O artigo em questão tinha sido primeiramente publicado no Jornal do Comércio, na Bahia, e fora enviado à revista pelos alunos da Faculdade de Direito de Niterói ao presidente Getúlio Vargas. 
mens e da sua vida profana e desregrada, porque só assim poderiam, com amor e confiança, transmitir um pouco dos sentimentos do coração puro e santo de mulheres indenes das imperfeições do mundo para o coraçãozinho do filho. Além de desalojar as mulheres do recesso sagrado do lar, afirmavam que o trabalho feminino apresentava outro aspecto negativo que era o de impedir novos casamentos, pois a cada mulher que ocupava um emprego, este deixava de ser atribuído para os homens que, por esse motivo, não se casavam.

Afirmavam que a independência econômica daria às mulheres uma situação de liberdade que as poderia iludir e as acovardar perante os encargos do matrimônio, bem como as faria querer limitar, senão eliminar o número de filhos. As solteiras poderiam se sentir felizes com a liberdade e a autonomia financeira conseguida por uma profissão e, por isso, rejeitariam o casamento. O mesmo não se daria com os homens que, assim que resolviam sua situação econômica, sonhavam em casar-se.

A limitação do número de filhos não era objeto das cogitações masculinas, partindo sempre das mulheres essa exigência. Isso representava um risco social para o país, que precisava de homens fortes para o seu desenvolvimento e não se deveria permitir que as mulheres ocupassem cargos públicos, ocasionando transtornos ao segmento masculino, pois "a mulher, pela alta missão que lhe compete na sociedade, deve merecer do homem e, sobretudo, do Estado, todas as atenções e cuidados que a dignifiquem e que lhe proporcionem, tanto quanto possível, um ambiente feliz como filha, noiva, esposa e mãe" (FALCÃO, 1941, p. 63).

Nos anos 1940, a revista $O$ Estudante, publicada em São Paulo, apresentava várias crônicas femininas escritas pela colaboradora Liloca Amaral, que discutia as questões relativas aos direitos das mulheres nos anos que corriam. $\mathrm{O}$ voto já estava assegurado, havia alguns anos, além de que o número de mulheres no mercado de trabalho, representado em especial pelo magistério, era grande, assim como sua frequência nas Escolas Normais. Nas crônicas, Liloca Amaral tratou de assuntos variados, como a futilidade feminina, os péssimos hábitos de mulheres da elite, contrapondo com a elegância e recato dos velhos tempos. Também abordava questões como educação e instrução para o sexo feminino e a inserção no campo profissional, principalmente num período em que os espaços ocupados pelos homens estavam vazios, com a população masculina envolvida com a guerra:

O preconceito da mulher moderna que trabalha e exerce profissões liberais, está infelizmente bastante arraigado na sociedade [...]. Com a tremenda destruição que assola o mundo, a mulher fatalmente substituirá os homens 
que ora se perdem nos campos de batalha. De modo que, por força das circunstâncias, ela terá de sair da meia escravidão em que tem vivido até hoje, para iniciar uma fase nova sobre a face da Terra (O ESTUDANTE, 1943, p. 24).

Para a articulista, apesar das constatações, as mulheres eram escravas e heroínas por terem de fazer prodígios para manter o lar e cuidar da família. Concordava que cabia à mulher a formação da alma e do caráter dos filhos, para isso, em pleno século XX, mais do que nunca, precisava de instrução. Argumentava que a independência trazia benefícios inegáveis para as mulheres, do ponto de vista daquelas que escreviam ao jornal, o que não era compartilhado pelos homens que preferiam as mulheres mantidas na ignorância e na submissão por temerem sua inserção profissional e sua independência.

A cronista ainda observava que os homens mostravam em relação à independência feminina uma atitude de descrédito e antagonismo. Isso transparece no artigo de um colaborador anônimo que escreveu ao jornal lamentando o que denominava a "falsa independência feminina", que deslocara a mulher do seu verdadeiro papel de mãe e de esposa:

É bem verdade que a educação moderna veio contribuir para a evolução da mulher em muitos sentidos. Hoje, ela já não teme o futuro. Enfrenta-o serena, capaz, na certeza de poder se defender com seu trabalho, com a sua atividade, com sua instrução. Mas, se ganhou em preparo, em atividade, perdeu pelo coração. A mulher de hoje não tem a meiguice, o carinho, o desvelo da mulher de ontem. Ontem ela era toda aflição, toda candura, fazia de seu lar um poema de doces canções; hoje, é dinâmica, viva, sem os encantos próprios de seu sexo. (...). Enquanto a mulher não se compenetrar do seu verdadeiro papel de mãe educadora, preparando gerações futuras, os cataclismos que assolam o mundo, tudo devastando, tudo destruindo, continuarão em sua obra demolidora, como um anátema à falsa independência que tirou à mulher o seu símbolo de amor e ternura! (O ESTUDANTE, 1943, p. 28).

Mesmo com os argumentos contrários à educação feminina, um dos seus principais redutos nos anos 1930/40, as escolas normais, havia se disseminado por todo o estado de São Paulo, inaugurando cursos nas cidades do interior, tanto oficiais como particulares. Nas escolas pertencentes ao ensino público, o regime coeducativo vinha se tornando uma realidade, o que inclusive era defendido pelo Poder Público devido à economia que representava para o Estado. 
A imprensa católica e os órgãos oficiais haviam dedicado grande atenção à coeducação, mas a revista $O$ Estudante revelou omissão quanto ao assunto. $\mathrm{Na}$ década de 1940, o costume de manter as mulheres nos lares e os homens de dirigirem os destinos da nação continuou separando os sexos nas escolas e na vida social. Os avanços femininos foram pautados pela lentidão e falta de reconhecimento social. A obtenção do direito a votar e serem votadas nos anos 1930 foi um paliativo que não assegurou verdadeira autonomia. As conquistas das décadas iniciais diluíram-se na avalanche política. Havia novamente triunfado o conservadorismo.

O magistério alicerçou-se como trabalho feminino em definitivo principalmente no ensino primário e pré-primário e manteve as prerrogativas conquistadas. Os homens concentraram-se mais no ensino secundário e superior, que foram gradativamente feminizando-se em algumas áreas, como a da educação. A sociedade masculina aceitou sem mais protestos, com exceção de uma ou outra voz isolada, a profissão de professora. O poder público regulamentou as horas de trabalho em meio período diurno para que as mulheres também pudessem cuidar da casa e fez algumas concessões trabalhistas, como férias e salários não diferenciados, pois, afinal, agora eram eleitoras. Portanto, a diferenciação de gênero pautou com suas imposições a hierarquização sexista da sociedade brasileira. Nunca houve um real espaço para que as mulheres pudessem se utilizar de seu potencial para o desenvolvimento da nação, e muitos talentos permaneceram e, ainda hoje, permanecem soterrados sob o manto da desigualdade e ausência de oportunidades que somente a educação pode oferecer.

\section{Algumas considerações}

As revistas femininas propugnaram o voto e a emancipação; exigiram a instrução e a profissionalização como um direito das mulheres. Porém, o papel no lar sobrepunha-se a qualquer outro que pudessem desempenhar à perfeição. Esse era realmente o trabalho valorizado e qualquer tentativa de emancipação ou qualquer profissão que pudesse afastá-las desse campo era vista com desconfiança.

A imprensa brasileira, por meio dos impressos de menor circulação e alcance, não mostrava a educação feminina e a feminização do magistério como resultado de reiteradas reivindicações das mulheres em ocupar um espaço profissional. O teor de seu conteúdo definia o Brasil como um país omisso em relação à educação feminina e resistente à sua saída do espaço doméstico. Transparecia, 
nessa imprensa, uma masculinidade imposta à sociedade como modelo padrão por excelência, com os homens dirigindo a nação e a vida das mulheres. Nas entrelinhas se esboçava um avanço sutil das mulheres em direção a um espaço profissional que poderiam conquistar sem lutas inglórias e desgastantes, o qual lhes permitiria manter o casamento como suprema aspiração de suas vidas. Se, a princípio, a educação lhes fora vedada e considerada como inútil para o que delas se esperava, exercer o ofício de ensinar foi certamente uma conquista.

O magistério, com as aberturas tornadas possíveis por algumas mudanças nas mentalidades, não foi tão facilmente acessível como sempre se acreditou. O trabalho feminino no magistério primário também implicou em resistência e significou o resultado dos primeiros passos dados pelas mulheres no rumo de sua profissionalização. Para as mulheres, a situação de inferioridade em que viviam no espaço privado estendeu-se ao espaço público, tendo como agravante as dificuldades oriundas do meio familiar, representadas pela dupla jornada de trabalho e o cuidado com a família. Esculpia-se assim uma ambiguidade em relação ao sexo feminino: se, por um lado, existia o desejo de serem esposas e mães; por outro, o anseio de fazer parte da população economicamente ativa significava deixar o primeiro espaço ao abandono. Em vista disso, a crítica feminista dedicou-se a estudar a fundo as questões de identidade e diferença e a não separação entre o espaço público e o espaço privado, buscando o fortalecimento de uma cultura não sexista e rejeitando os antigos paradigmas de submissão e opressão. Aos poucos, serem rainhas do lar já não bastava. No entanto, a profissionalização das mulheres continuou alvo de preconceitos, como no artigo intitulado "O Eterno Feminino", publicado na Revista Ilustrada, em 1886, o qual afirmava que sua esfera de ação profissional deveria ser ampliada, mas não muito, finalizando que "a mulher não deve se intrometer em lutas políticas". (Apud BUITONI, 1981, p. 18).

Os fragmentos iconográficos, ou os escritos do passado histórico, de fontes hoje silenciadas pela voragem dos anos, permitem estudar as mulheres em veículos diferenciados que popularizavam toda forma de palavra impressa dirigida a ambos os sexos. Nas relações de alteridade, vale a pena refletir sobre como homens e mulheres, na ordem burguesa, ao longo das décadas, decodificavam os sentidos e atribuíam novos significados à vida cotidiana. As revistas e pequenos jornais de circulação restrita compuseram novos rearranjos sociais e alteraram os rumos dos destinos impostos ao sexo feminino? A história das mulheres ainda não foi suficientemente desvendada para podermos afirmar com certeza. 


\section{REFERÊNCIAS}

ANUÁRIO DO ENSINO DO ESTADO DE SÃO PAULO 1911/1912. São Paulo, Imprensa Oficial do Estado, 1912.

ALMEIDA, J. S. de. Mulher e Educação: a paixão pelo possível. São Paulo: Editora da Unesp, 1998.

ALMEIDA, J. S. de. Vestígios para uma reinterpretação do magistério feminino em Portugal e no Brasil a partir do século XIX. In: SAVIANI, D.; ALMEIDA, J. S. de; SOUZA, R. F. de; VALDEMARIN, V.T. O legado educacional do século XIX. 3. ed. Campinas, Autores Associados, 2015.

BERRA, F. A. Se as mulheres são preferíveis, ou não, aos homens para dar aos meninos a instrução primária. Revista de Ensino, São Paulo, p. 20, 1910. Acervo da Biblioteca John Kennedy.

BUITONI, D. H. S. Mulher de Papel: a representação da mulher pela imprensa feminina brasileira. São Paulo: Loyola, 1981.

BUITONI, D. H. Imprensa feminina. São Paulo: Ática, 1986.

CAMPOS, R. D. de. No rastro de velhos jornais: considerações sobre a utilização da imprensa não pedagógica como fonte para a escrita da história da educação. Revista Brasileira de História da Educação, Campinas, SP, v. 12, n. 1 (28), p. 45-70, jan./abr. 2012.

DORA LICE (pseud.). O calvário de uma professora. São Paulo, Estabelecimento Grafhico Irmãos Ferraz. 1928.

FALCÃO, A. N. A mulher e o serviço público. Formação - Revista Brasileira de Educação, p. 60-65, jan. 1941.

FORMAÇÃO - Revista Brasileira de Educação, São Paulo, p. 60-65, jan. 1941.

GUASTINI, M. São Paulo de ontem e de hoje. Ella, n. 1, 15 abr. 1936.

LIMA, S. L. L. Espelho da mulher: Revista Feminina (1916-1925). Tese (Doutorado em História Social) - FFLCH/USP. 1991.

MAGALDI, A. M. B. de M. Vozes católicas: um estudo sobre a presença feminina no periódico A Ordem (anos 1930-40). In: LÔBO, Y.; FARIA, L. (Orgs.). Vozes femininas do Império e da República. Rio de Janeiro, Quartet: FAPERJ, 2008.

MAIA, J. Normalistas. Revista de Ensino, São Paulo, p. 924, out. 1902. Acervo da Biblioteca John Kennedy.

MASCARO, S. de A. A Revista Feminina: imagens de mulher (1914-1930), Dissertação (Mestrado em Ciências da Comunicação) - ECA, USP. 1982.

O ESTUDANTE, São Paulo, p. 20, jul. 1943. Acervo da Biblioteca John Kennedy. 
O ESTUDANTE, São Paulo, p. 28, jan./fev. 1943. Acervo da Biblioteca John Kennedy. REVISTA DE ENSINO, São Paulo, 1902-1912. Acervo da Biblioteca John Kennedy.

REIS, M. C. D. Tessitura de Destinos: mulher e educação, São Paulo 1910/20/30. São Paulo: EDUC, 1993.

RICOEUR, P. Interpretações e Ideologias. Rio de Janeiro, Francisco Alves, 1988.

RICOEUR, P. O conflito das interpretações: ensaios de hermenêutica. Rio de Janeiro, Imago, 1978.

Texto recebido em 21 de fevereiro de 2017.

Texto aprovado em 07 de maio de 2017. 